\title{
Visually evoked responses in multiple sclerosis ${ }^{1}$
}

\author{
E. T. RICHEY, ${ }^{2}$ K. A. KOOI, AND W. W. TOURTELLOTTE \\ From the Laboratory of Electroencephalography, Neuropsychiatric Institute, University of Michigan Medical \\ Center, Ann Arbor, Michigan, U.S.A.
}

SUMMARY Visually evoked cerebral responses (VERs) from the occipital and central areas were compared between 50 patients with multiple sclerosis and 50 control subjects. The average peak latencies of four occipital components (OII-OV) and two central ones (CIV and CV) were significantly delayed. In no instance was the amplitude significantly different. Routine EEGs were either entirely normal (16) or showed only minor findings (10) in 26 patients. Of this group, nine showed abnormal VERs. Seventeen patients had clinical symptoms or signs which pointed to spinal cord involvement only; nonetheless, eight in this group had abnormal responses. Inasmuch as changes in visually evoked potentials are not directly dependent upon the presence of a demonstrable field defect, the technique may be useful in detecting otherwise occult cerebral lesions.

Because multiple sclerosis frequently produces visual defects, it is natural to anticipate concomitant changes in visually evoked cerebral responses. However, a preliminary study of a small group of patients revealed that, while there were evident changes in some patients, they were not necessarily those having signs of involvement of the visual system. In the present study, an expanded sample of patients with multiple sclerosis was examined in order to ascertain (1) the effect of the disease upon the latencies and amplitudes of visually evoked waves, (2) the proportion of patients who have clearly abnormal responses, (3) the clinical correlates, if any, of the alterations, and (4) their relation to routine electroencephalographic findings.

\section{SƯBJECTS AND METHODS}

Visually evoked responses (VERs) were obtained on 50 patients with multiple sclerosis ( 35 females, 15 males) and 50 normal subjects ( 35 females, 15 males). The two samples were matched with respect to age (averages of $40 \cdot 2$ years each). Control subjects were in good health, without neurological illness, and not on any medication. All patients were hospitalized during a period of exacerbation of their disease. The final diagnosis of multiple sclerosis was made in each case by the Neurology Service.

\footnotetext{
${ }^{1}$ Supported in part by research grant NB-02560 from the National Institute of Neurological Diseases and Blindness, U.S.P.H.S., National Institutes of Health, and a grant from the Michigan Chapter of the National Multiple Sclerosis Society.

${ }^{2}$ Present address: Jackson Memorial Hospital, University of Miami Medical School, EEG Laboratory, Miami, Florida 33136, U.S.A.
}

The same procedure was followed in all subjects and patients. A resting EEG was obtained along with the evoked response study. The face of a Grass PS-2 photic stimulator lamp enclosed in a double walled box was placed $5 \mathrm{~cm}$ before the open eyes. No responses were detectable in control runs with the light covered. Background light intensity was adjusted to approximately one foot candle.

Routine EEGs were run on a Grass Model III Electroencephalograph. The evoked responses were summated with the Mnemotron Computer of Average Transients. Three computer runs were obtained. The averaging period for the first two runs was $250 \mathrm{msec}$ and for the third was $125 \mathrm{msec}$. Light flashes were randomized and given one every 4 to $6 \mathrm{sec}$ to a total of 50 for the first two runs and one every 0.5 to $1 \mathrm{sec}$ to a total of 300 for the third run.

During the first run, data were obtained from the following electrode positions: left and right frontal, central, occipital, and temporal areas. The reference was joined-ears. Occipital electrodes were placed $3 \mathrm{~cm}$ above and $3 \mathrm{~cm}$ lateral to the inion. Central electrodes were placed $4 \mathrm{~cm}$ from the midline in the interaural plane. Data from the second and third computer runs were used to substantiate the initial observations and further to assess possible ocular and myogenic artefacts. The summated responses were displayed on a Tektronix cathode ray oscilloscope and photographed with a Hathaway oscilloscope camera.

Individual components of the evoked responses from the occipital and central regions were used for analysis. Both left and right-sided measurements were obtained with the left-sided values being used for statistical analysis (Kooi, Güvener, and Bagchi, 1965). The first five major occipital waves in either a negative or positive direction after the stimulus were studied. The vertex sharp wave 
(CV), a surface-negative deflection, was evaluated from the central response. The preceding positive wave (CIV) was also studied. Ranges for latencies and amplitudes of these occipital and central components are based on previous studies by Kooi and Bagchi (1964) and Kooi et al. (1965), and the control data obtained from the present study. CIV and CV were not measured if the eye blink artefact extended into the central regions.

Amplitude orders were established for the major components of the occipital and central response in the patient and control groups. Waves having the greatest, second greatest, and third greatest amplitudes in both negative and positive directions were identified and their latencies plotted (Fig. 1A and B and Fig. 2A and B).

The first major wave of the normal occipital VER is a surface-negative deflection (OI) having a general latency range of 30-70 msec. As seen from Fig. 1A, 2 clusters of latencies fall within the general range of OI. The intermediate wave previously described by Richey, Kooi, and Waggoner (1966) is responsible for the second of these. The next major deflection is a surface-positive one (OII) with a latency of $50-100 \mathrm{msec}$, a second surface negative deflection (OIII) with a latency range of 70-125 msec, then a second surface-positive component (OIV) having a latency range of $100-150 \mathrm{msec}$, and, finally, a surfacenegative deflection (OV) with a latency range of 125-190 msec. Later occipital components were not measured and evaluated statistically. Latency ranges of CIV and $\mathrm{CV}$ are $95-115 \mathrm{msec}$ and $110-165 \mathrm{msec}$ respectively. These 2 deflections are seen in Fig. 2A. Earlier central components were also not evaluated statistically.

Latency was determined by measuring the interval between the instant of the stimulus and the peak of the appropriate major deflection within each range. Amplitude for the first occipital component was measured from the averaged base line to the peak of OI. For each succeeding component, in both occipital and central regions amplitude was determined by measuring from the peak of the preceding wave to the peak of the wave being measured. In a few instances, one or more components could not be identified. Measurements of selected waves in occipital and central regions have shown high orders of reliability in earlier test-retest studies with correlation coefficients of .91 to .96 for latencies and of .87 and .97 for amplitudes. Reproducibility is enhanced through the use of eyes-open technique which reduces variance from 'background' activity as well as factors related to the structure of the eyelids.

The VER was classified as abnormal if there was (1) absence of discernible response, (2) a unilateral absence or a left-right voltage difference of greater than $75 \%$ of one or more waves in homologous areas, or (3) a distinct left-right asymmetry of form confirmed by a difference in peak latency of the wave of more than $15 \mathrm{msec}$ in homologous areas, or (4) in the case of CV, an absolute latency exceeding $170 \mathrm{msec}$ (Kooi and Bagchi, 1964; Kooi et al., 1965). Three of the normal controls had responses which met these criteria, all because of asymmetries of form.

\section{RESULTS}

Twenty-six of the 50 resting EEGs in the patient group were either entirely within normal limits or showed only borderline non-specific findings. $\stackrel{\mathcal{D}}{\mathcal{C}}$ Twenty EEGs showing primarily theta or theta-o delta patterns in the temporal regions were classified $\stackrel{\mathscr{C}}{\subseteq}$ as mildly abnormal. Three records were interpreted $\widehat{\widehat{C}}$ as moderately abnormal because of an excess of ${ }_{\omega}^{D}$ slow components in the background pattern plus $\widehat{O}$ temporal theta-delta transients. One record was markedly abnormal because of a slow background pattern $(7-8 \mathrm{~Hz})$ plus delta activity shifting between $\Rightarrow$ the temporal regions. In no case were spikes or spike-wave discharges seen.

Figures 1 and 2 show the peak latencies of the $\frac{\bar{\sigma}}{}$ major waves in occipital and central regions selected $\overline{\bar{p}}$ according to relative amplitude in control and $\mathbb{Q}$ patient groups. By inspection there is more variability in the patient group with a resultant lack of ${ }^{\mathcal{S}}$ definition of the clusters representing each of the major components previously described.

Table 1 shows the analysis of average latencies $\stackrel{\omega}{\omega}$ for the five occipital and two central components. Every component shows a statistically significanto delay in the patient group with the exception of OI. $\omega$ Further statistical evaluation revealed that the latency of OI was not significantly different in the N patients and controls when the patient group was restricted to the 18 cases with visual signs-centralo scotomata (11), enlarged blind spots (four), hom 9 nymous field defects (three), optic atrophy (two), bilateral nonhomonymous field defects (one).

Although there was considerable variation amplitudes throughout the patient group and mamy individual cases showed definite left-right amplitude asymmetries of one or more components, in noneo of the statistical comparisons of either the right or the left side were average amplitudes of the five occipital or two central components statistically $\frac{0}{\mathbb{D}}$ different from comparable components in the $\varrho$ control population. When patients with and withoutö visual system damage were compared, no significant 3 differences emerged between average latencies or amplitudes of any of the seven components studied

Figure 3 shows typical central and occipital responses in a normal subject.

Figures 4 to 6 are examples of the evoked response in the central and occipital regions of three multiple sclerosis patients.

Table 2 shows a comparison between all cases of multiple sclerosis versus cases by neurologicale categories in respect to incidences of normal VERs. $\rightarrow$ The proportion of deviant responses was not signi-Oㅡㅡ. ficantly different in the group of 18 patients who had evidence of visual system damage as compared witho the group as a whole. The 10 brain-stem dysfunction 0 cases showed primarily dissociative nystagmus. OfN five patients presenting with an organic mentalo 


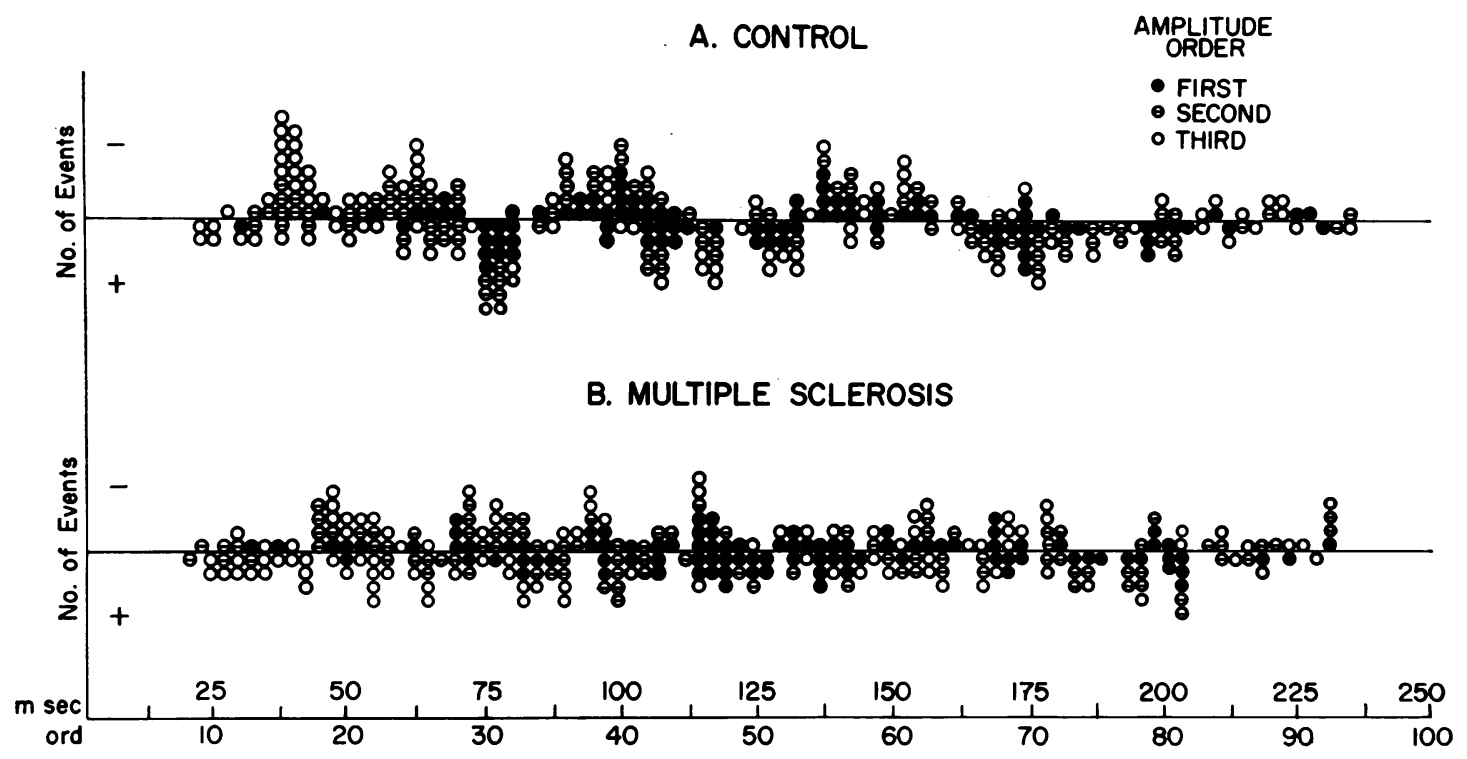

FIG. 1. Amplitude orders and latencies of major waves in the occipital region, three surface-negative and three surfacepositive for each subject. A: control subjects, $N=50$. B: patients with multiple sclerosis, $N=49$. Note that the individual components (latencies given in text) are not well delineated in the patient group.

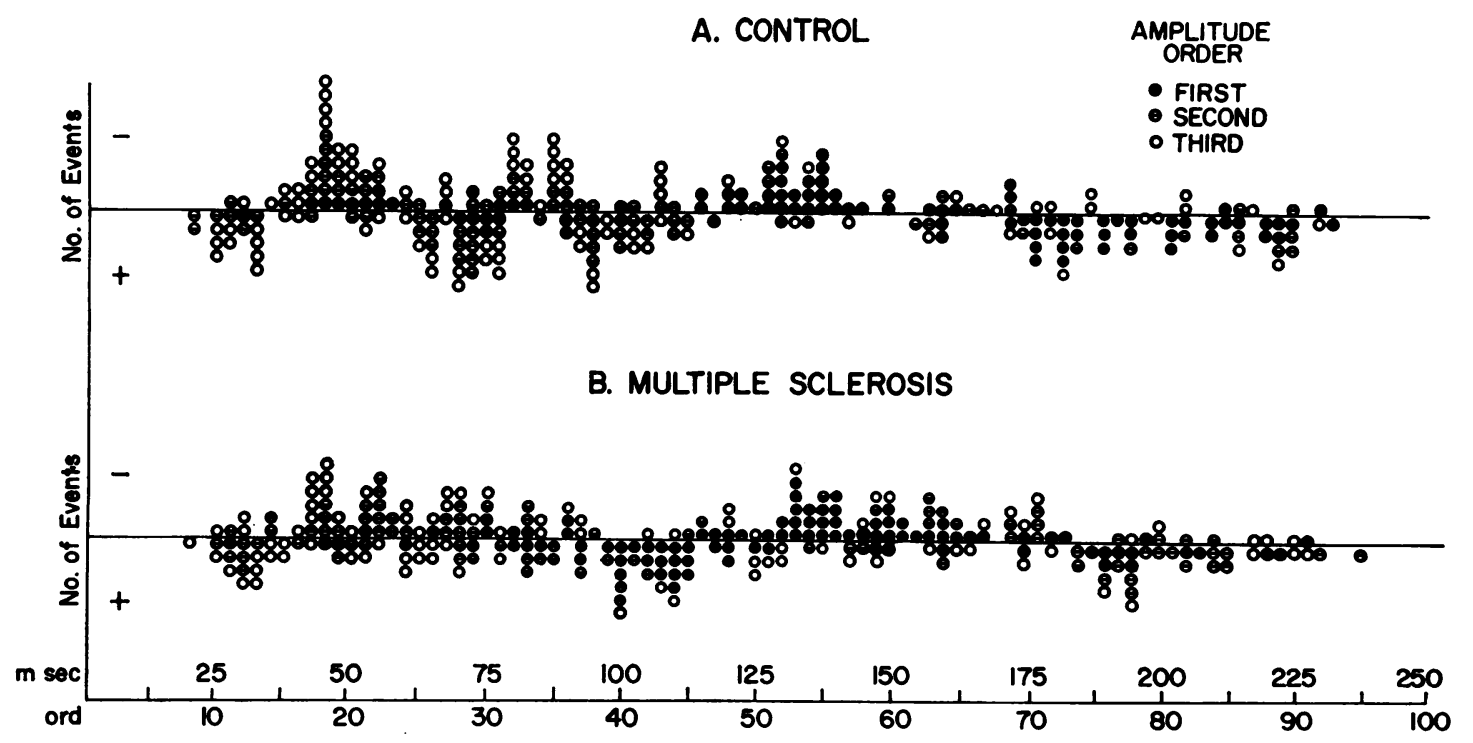

FIG. 2. Amplitude orders and latencies of major waves in the central region, three surface-negative and three surfacepositive for each subject. A: control subjects, $N=46$. B: patients with multiple sclerosis, $N=49$. (See under Fig. 1.) 
TABLE 1

AVERAGE LATENCIES OF VERS IN PATIENT AND CONTROL GROUPS

\begin{tabular}{|c|c|c|c|c|c|c|c|c|c|c|c|c|c|c|}
\hline & \multicolumn{2}{|c|}{$O I$} & \multicolumn{2}{|c|}{$O I I$} & \multicolumn{2}{|c|}{$O I I I$} & \multicolumn{2}{|c|}{$O I V$} & \multicolumn{2}{|c|}{$O V$} & \multicolumn{2}{|c|}{$C I V$} & \multicolumn{2}{|l|}{$C V$} \\
\hline & (msec) & $(n o .)^{1}$ & (msec) & (no.) & (msec) & (no.) & (msec) & (no.) & (msec) & (no.) & (msec) & (no.) & (msec) & (no.) \\
\hline $\begin{array}{l}\text { Multiple sclerosis } \\
\text { Control } \\
\text { t }\end{array}$ & $\begin{array}{r}52 \cdot 5 \\
51 \cdot 3 \\
.48\end{array}$ & $\begin{array}{l}44 \\
50\end{array}$ & $\begin{array}{c}81 \cdot 8 \\
75 \cdot 3 \\
2 \cdot 23 \\
<\cdot 05\end{array}$ & $\begin{array}{l}45 \\
49\end{array}$ & $\begin{array}{c}105 \cdot 5 \\
95 \cdot 3 \\
3 \cdot 52 \\
<\cdot 001\end{array}$ & $\begin{array}{l}46 \\
49\end{array}$ & $\begin{array}{c}132 \cdot 8 \\
118 \cdot 0 \\
4 \cdot 77 \\
<\cdot 001\end{array}$ & $\begin{array}{l}44 \\
47\end{array}$ & $\begin{array}{c}160 \cdot 5 \\
148 \cdot 0 \\
3 \cdot 50 \\
<\cdot 001\end{array}$ & $\begin{array}{l}40 \\
47\end{array}$ & $\begin{array}{c}114.5 \\
103.5 \\
3.62 \\
<.001\end{array}$ & $\begin{array}{l}49 \\
42\end{array}$ & $\begin{array}{c}151 \cdot 8 \\
136.0 \\
4 \cdot 31 \\
<\cdot 001\end{array}$ & $\begin{array}{l}49 \\
46\end{array}$ \\
\hline
\end{tabular}

No. of individuals.

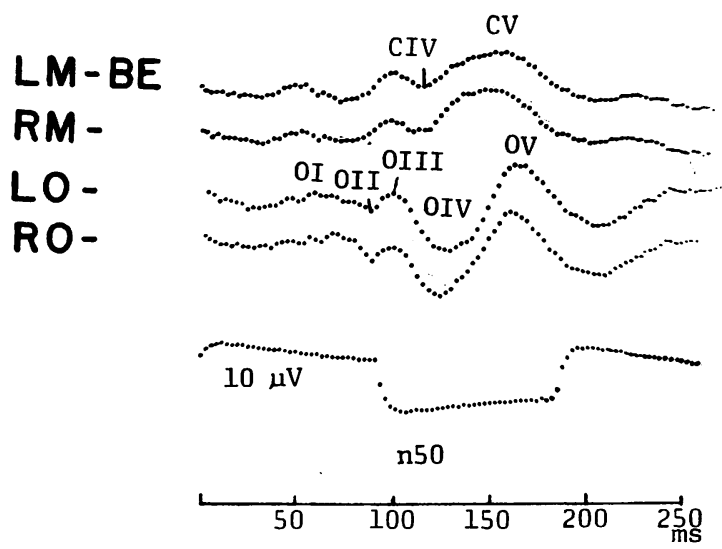

FIG. 3. Typical responses in the central and occipital regions of a normal subject (F26). The seven waves evaluated in this study âre indicated.

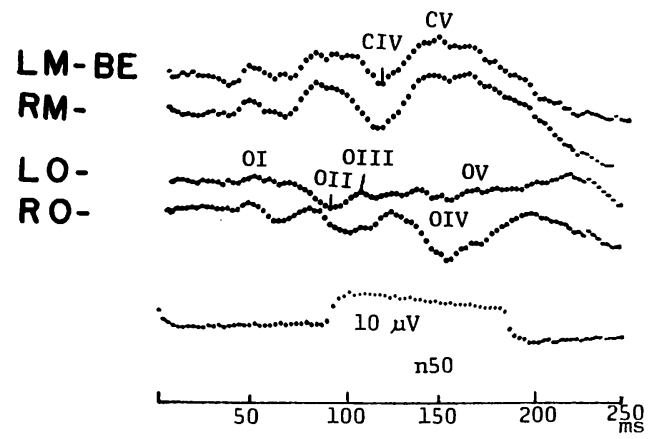

FIG. 4. The two central components in this multiple sclerosis patient (F30) were normal. Note the delay of OIII on the left side.

syndrome, four had deviant responses. One of the four, who also had bilateral optic atrophy, had no detectable evoked response but showed a normal resting electroencephalogram and a normal electro-

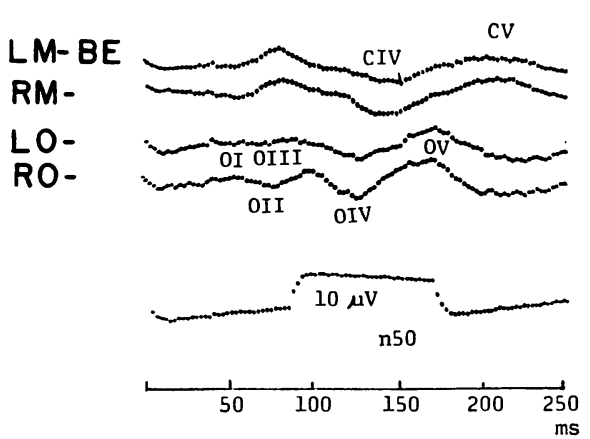

FIG. 5. This patient (M45) shows considerable delay $\stackrel{\mathbb{D}}{\text { f }}$ the two central components with CV occurring at 200 af $d$ 은 $207.5 \mathrm{msec}$ on the left and right sides respectively. Therejsalso a slight latency and amplitude asymmetry of OYH.C This patient had a mild organic mental syndrome.
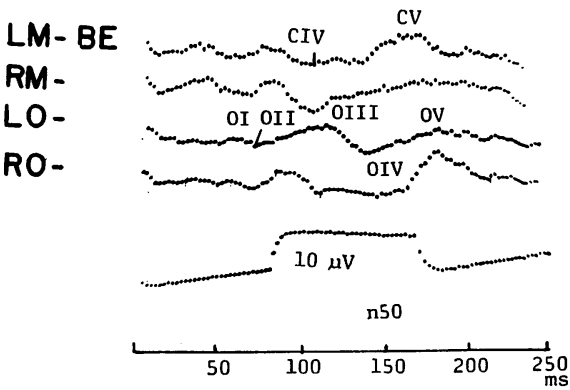

FIG. 6. In this patient (F26) there is an asymmetry ino culmination of $\mathrm{CV}$ with the delay occurring on the right side. Also, note asymmetry of OIII with this componento being delayed on the left side.

retinogram. The remaining three had delayedos culmination of CV. It is noteworthy that eight patients who had spinal cord signs only showedn abnormal evoked patterns. Three patients of the 
TABLE 2

VERS IN MULTIPLE SCLEROSIS

\begin{tabular}{|c|c|c|c|c|c|}
\hline & \multirow{2}{*}{$\begin{array}{l}\text { All cases } \\
(n=50)\end{array}$} & \multicolumn{4}{|c|}{ Categories by neurological signs ${ }^{1}$} \\
\hline & & $\begin{array}{c}\text { Visual } \\
(n=18)\end{array}$ & $\begin{array}{l}\text { Brain-stem dysfunction } \\
\quad(n=10)\end{array}$ & $\begin{array}{l}\text { Organic mental syndrome } \\
\qquad(n=5)\end{array}$ & $\begin{array}{l}\text { Spinal cord signs only } \\
\quad(n=17)\end{array}$ \\
\hline \multicolumn{6}{|l|}{ VERs } \\
\hline Normal & 30 & 10 & 8 & 1 & 9 \\
\hline Abnormal & 20 & 8 & 2 & 4 & 8 \\
\hline \multicolumn{6}{|l|}{ Types $^{1}$} \\
\hline Absent VER & & 1 & 0 & 1 & $\mathbf{0}$ \\
\hline L-R amplitude difference $>75 \%$ & & 3 & 1 & 1 & 1 \\
\hline L-R latency difference $>15 \mathrm{msec}$ & & 6 & 0 & 1 & 3 \\
\hline Latency $\mathrm{CV}>170 \mathrm{msec}$ & & 5 & 2 & 3 & 5 \\
\hline
\end{tabular}

Not mutually exclusive.

eight had normal resting electroencephalograms. The EEG results are compared with the VERs in Table 3.

TABLE 3

VERS AND EEG FINDINGS

\begin{tabular}{lcc}
\hline & \multicolumn{2}{c}{ EEG } \\
\cline { 2 - 3 } & Normal & Abnormal \\
\hline VERs & 17 & \\
Normal & 9 & 13 \\
Abnormal & 9 \\
\hline
\end{tabular}

DISCUSSION

It appears that multiple sclerosis commonly affects photically-induced cerebral responses, the average latency of every component examined except OI being significantly delayed. Moreover, the changes were of sufficient extent to be considered abnormal in $40 \%$ of the patients as compared with $6 \%$ in a control group. The fact that significant deviations occur in patients who, from a clinical standpoint, have evidence of only spinal cord involvement or who have normal resting electroencephalograms, or both, points to areas of potential clinical application.

The apparent lack of relationship between clinical evidence of involvement of the visual system and changes in the VER, especially in respect to the early occipital components, warrants comment. Cigánek (1961) called the first three occipital waves the primary response and assumed them to be evoked by a stimulus following the specific pathway. Kooi et al. (1965), in studying patients with and without homonymous field defects, found alterations of the response with but few exceptions in the former group, disturbances in the latencies of OI and OII being the most characteristic change. These earlier results, taken together with the present findings, suggest that cortical responses elicited by diffuse binocular photic stimulation are more likely to be distorted by central than by peripheral lesions of the visual pathway. In keeping with this is the fact that both patients in the present series with homonymous field defects had deviant VERs. Questions remain, however, as to the importance of such factors as size of the visual defect and its location within the visual field.

It is evident from our data that alterations of the VER occur commonly in patients who have no evidence of visual pathway damage whatsoever, suggesting that conduction defects within nonspecific cerebral or, more strictly, non-primary pathways may be responsible for some of the observed deviations. In this connection, however, it is pertinent to consider another line of reasoning which offers an alternative explanation for the dissociation between the clinical signs and electrical phenomena. It has been shown in cases recovering from an acute exacerbation of the illness in which the somatosensory system has been affected that the configuration of the cerebral response to nerve stimulation may continue to improve after sensory function has returned to apparent normality (Baker, Sances, and Larson, 1966; Namerow, 1968), suggesting the presence of mechanisms that compensate for disturbances of nerve transmission attendant upon lesions directly within the primary sensory pathway. Without prejudice to this theory, which may well be applicable in certain instances, our group data would not seem to be satisfactorily viewed in this light, inasmuch as no appreciable differences were found between patients with and without overt signs of involvement of the visual pathway.

Appreciation is extended to Dr. B. K. Bagchi for helpful comments and suggestions. 


\section{REFERENCES}

Baker, J. B., Sances, A., and Larson, S. J. (1966). Neurophysiological evaluation of patients with multiple sclerosis. Marquette Med. Rev., 32, 37-39.

Cigánek, C. (1961). The EEG response (evoked potential) to light stimulus in man. Electroenceph. clin. Neurophysiol., 13, 165-172.

Kooi, K. A., and Bagchi, B. K. (1964). Visual evoked responses in man: normative data. In Sensory Evoked
Responses in Man. Edited by R. Katzman. Ann. N.Y Acad. Sci., 112, 254-269.

Kooi, K. A., Güvener, A. M., and Bagchi, B. K. (1965) Visual evoked responses in lesions of the higher optie pathways. Neurology (Minneap.), 15, 841-854.

Namerow, N. S. (1968). Somatosensory evoked responses if? multiple sclerosis patients with varying sensory loss? Neurology (Minneap.), 18, 1197-1204.

Richey, E. T., Kooi, K. A., and Waggoner, R. W. (1966) Visually evoked responses in migraine. Electroenceph. clinâ Neurophysiol., 21, 23-27. 